\title{
A soyabean diet does not modify the activity of brown adipose tissue but alters the rate of lipolysis in the retroperitoneal white adipose tissue of male rats recovering from early-life malnutrition
}

\author{
Adriene Alexandra Paiva ${ }^{1}$, Jaline Zandonato Faiad ${ }^{1}$, Marina Satie Taki ${ }^{1}$, Silvia Regina de Lima Reis ${ }^{1}$, \\ Letícia Martins Ignácio de Souza ${ }^{1}$, Maísa Pavani dos Santos ${ }^{2}$, Valéria Ernestânia Chaves ${ }^{3}$, \\ Nair Honda Kawashita ${ }^{2}$, Helena Coutinho Franco de Oliveira ${ }^{4}$, Helena Fonseca Raposo ${ }^{4}$, \\ Everardo Magalhães Carneiro ${ }^{4}$, Márcia Queiroz Latorraca ${ }^{1}$, Maria Helena Gaíva Gomes-da-Silva ${ }^{1}$ \\ and Maria Salete Ferreira Martins ${ }^{1 *}$ \\ ${ }^{1}$ Departamento de Alimentos e Nutrição, Faculdade de Nutrição, Universidade Federal de Mato Grosso, Cuiabá, \\ Mato Grosso, Brazil \\ ${ }^{2}$ Departamento de Química, Instituto de Ciências Exatas e da Terra, Universidade Federal de Mato Grosso, Cuiabá, \\ Mato Grosso, Brazil \\ ${ }^{3}$ Departamento de Ciências Básicas em Saúde, Faculdade de Ciências Médicas, Universidade Federal de Mato Grosso, \\ Cuiabá, Mato Grosso, Brazil \\ ${ }^{4}$ Departamento de Anatomia, Biologia Celular e Fisiologia, Instituto de Biologia, Universidade Estadual de Campinas, \\ Campinas-SP, Brazil
}

(Submitted 17 March 2011 - Final revision received 13 October 2011 - Accepted 13 October 2011 - First published online 12 December 2011)

\section{Abstract}

Nutritional recovery with a soyabean diet decreases body and fat weights when compared with a casein diet. We investigated whether the reduced adiposity observed in rats recovering from early-life malnutrition with a soyabean diet results from alterations in lipid metabolism in white adipose tissue (WAT) and/or brown adipose tissue (BAT). Male rats from mothers fed either 17 or $6 \%$ protein during pregnancy and lactation were maintained on $17 \%$ casein (CC and LC groups), 17\% soyabean (CS and LS groups) or 6\% casein (LL group) diets over $60 \mathrm{~d}$. The rats maintained on a soyabean diet had similar relative food intakes, but lower body and retroperitoneal WAT weights and a reduced lipid content in the retroperitoneal WAT. The insulin levels were lower in the recovered rats and were elevated in those fed a soyabean diet. Serum T3 concentration and uncoupling protein 1 content in the BAT were decreased in the recovered rats. The thermogenic capacity of the BAT was not affected by the soyabean diet. The lipogenesis rate in the retroperitoneal WAT was similar in all of the groups except for the LL group, which had exacerbated lipogenesis. The enhancement of the lipolysis rate by isoproterenol was decreased in white adipocytes from the soyabean-recovered rats and was elevated in adipocytes from the soyabean-control rats. Thus, in animals maintained on a soyabean diet, the proportions of fat deposits are determined by the lipolysis rate, which differs depending on the previous nutritional status.

Key words: Nutritional recovery: Soyabean diet: Adipose tissue: Rats

Soya-containing diets have been shown to alter several parameters involved in maintaining body homeostasis, energy expenditure and feeding behaviour ${ }^{(1-3)}$. Soya protein and isoflavone have been reported to reduce fat-pad weight by increasing uncoupling protein 1 (UCP-1) expression in brown adipose tissue (BAT) ${ }^{(4)}$. UCP-1 is a molecule that uncouples mitochondrial oxidative phosphorylation by bypassing the electrochemical gradient across the inner membrane from

\footnotetext{
Abbreviations: BAT, brown adipose tissue; C, control; CC, offspring born to and suckled by mothers fed a control diet that were fed a control diet after weaning; CS, offspring born to and suckled by mothers fed a control diet that were fed a soyabean diet with $17 \%$ protein after weaning; HOMA-IR, homeostasis model assessment of insulin resistance; LC, offspring of mothers fed a low-protein diet that were fed a control diet after weaning; LL, offspring of mothers fed a low-protein diet that were fed a low-protein diet after weaning; LP, low-protein; LS, offspring of mothers fed a low-protein diet that were fed a soyabean diet containing $17 \%$ protein after weaning; RWAT, retroperitoneal white adipose tissue; Tris, 2-amino2-hydroxymethyl-propane-1,3-diol; UCP-1, uncoupling protein 1; WAT, white adipose tissue
}

*Corresponding author: M. S. F. Martins, fax +55 653615 8811, email msfm.cba@gmail.com 
F1-ATPase and thereby dissipating energy as heat. This protein is involved in diet-induced thermogenesis and cold-induced non-shivering thermogenesis, and it also has a significant role in controlling energy expenditure and the whole-body energy balance $^{(5,6)}$. UCP-1 thermogenesis in BAT is under the direct control of the sympathetic nerves which are abundant in this tissue. The cellular event associated with the sympathetic activation of BAT thermogenesis is the binding of noradrenalin released from the sympathetic nerve terminals to $\beta$-adrenergic receptors ${ }^{(5)}$. Although the BAT thermogenic response is initiated by noradrenalin, thyroid hormone must be present ${ }^{(5,7)}$. The increase in BAT thermogenesis and the enhancement of fatty acid oxidation are accompanied by a simultaneous elevation in fatty acid synthesis ${ }^{(8,9)}$. The direct control of BAT lipogenesis by the sympathetic nervous system has been suggested because experiments have shown that fatty acid synthesis is rapidly increased upon stimulation of the ventromedial hypothalamic nucleus ${ }^{(9,10)}$ or by intermittent electrical stimulation of BAT sympathetic fibres ${ }^{(11)}$. In BAT, insulin stimulates fatty acid synthesis both in vivo ${ }^{(12)}$ and in vitro ${ }^{(13)}$, and its concentration in plasma changes in parallel with diet-induced changes. Therefore, during changes in diet-induced thermogenesis, the combined effect of the sympathetic outflow to the BAT and plasma insulin levels is probably of major importance with respect to the corresponding changes in lipogenesis ${ }^{(14)}$.

In addition to the effects on thermogenesis, a soya diet and its components appear to affect the metabolism of white adipose tissue (WAT) and to decrease the fat-pad weight ${ }^{(2,3)}$. Fat accumulation is determined by the balance between fat synthesis (lipogenesis) and fat breakdown (lipolysis/fatty acid oxidation). Fat storage occurs both through the direct uptake of circulating lipoprotein TAG, which are hydrolysed by lipoprotein lipase to NEFA, and local lipogenic pathways involving de novo synthesis from glucose and other precursors $^{(15)}$. It is well known that physiological factors, such as dieting or fasting, regulate fat synthesis and that insulin is the most important lipogenic hormone. Fat breakdown through the lipolysis pathway provides NEFA, which are used as fuel for other organs. Lipolysis is stimulated by the sympathetic nervous system and hormones such as adrenalin and glucagon. The action of catecholamines in WAT is dependent on the circulating adrenalin flux and/or noradrenalin from sympathetic innervations ${ }^{(16)}$. Thyroid hormone has profound effects on metabolic homeostasis, regulating both lipogenesis and lipolysis primarily by modulating adrenergic $\operatorname{activity}^{(17)}$.

Because of its reduced cost and elevated nutritional value, soyabean flour has been used as an alternative feed during recovery from early-life malnutrition ${ }^{(2)}$. Nutritional recovery with a casein diet produces several metabolic abnormalities that are also present in the metabolic syndrome. In contrast, rats recovered with a soyabean flour diet showed reduced proportions of fat deposits, even though the rats ate proportionally the same amount and exhibited lower energy expenditure than those fed with an isoprotein casein diet ${ }^{(2)}$. The mechanisms whereby a soyabean diet produced these effects during the recovery of early-life malnutrition are not completely clear. Thus, the present study investigates whether the reduced proportions of fat deposits observed in animals maintained on a soyabean diet are the result of alterations in lipid metabolism in WAT, BAT or both. Early-life malnutrition was achieved by maintaining the rats on low-protein (LP) diets during pregnancy and lactation. Post-weaning, the offspring were recovered with normal-protein isoenergetic diets using different protein sources (casein or soyabean).

\section{Materials and methods}

\section{Animals and diets}

The experimental procedures involving rats were performed in accordance with the guidelines of the Brazilian College for Animal Experimentation ${ }^{(18)}$ and were approved by the Ethics Committee at Mato Grosso Federal University (process no. 013714/09-0). Male and virgin female Wistar rats (aged 85-90 d) were obtained from the university's breeding colony. Mating was performed by housing one male with four females overnight, and pregnancy was confirmed by examining vaginal smears for the presence of sperm. Pregnant females were randomly separated, and from the 1st day of pregnancy until the end of lactation, they were fed isoenergetic diets containing $17 \%$ casein (control (C); $n$ 10) or $6 \%$ casein (LP; $n$ 15) as the protein source.

Spontaneous delivery occurred on day 22 of pregnancy, and at the age of $3 \mathrm{~d}$, large litters were reduced to eight pups (six or seven male and one or two female) to ensure a standard litter size per mother. After weaning (week 4), the males were divided into five groups: CC (offspring born to and suckled by mothers fed a $\mathrm{C}$ diet that were fed a $\mathrm{C}$ diet after weaning); CS (offspring born to and suckled by mothers fed a $\mathrm{C}$ diet that were fed a soyabean diet with $17 \%$ protein after weaning); LL (offspring of mothers fed a LP diet that were fed a LP diet after weaning); LC (offspring of mothers fed a LP diet that were fed a $\mathrm{C}$ diet after weaning); LS (offspring of mothers fed a LP diet that were fed a soyabean diet containing $17 \%$ protein after weaning). After weaning, the CC and CS groups contained pups from ten different litters, whereas the LC, LS and LL groups had pups from fifteen litters. The rats were kept in collective cages (four animals per cage totalling thirty-two rats per group), given free access to food and water and kept under standard lighting conditions ( $12 \mathrm{~h}$ light $-12 \mathrm{~h}$ dark cycle) at $24^{\circ} \mathrm{C}$ throughout the experimental period.

All diets used in the present study are described in Table 1. In the soyabean diet, adjustments were made to equalise carbohydrate, lipid and fibre contents and the energy value to those in the casein diet by removing soyabean oil and reducing fibre. Whole, inactivated soyabean flour was obtained by industrial processing (i.e. thermal treatment, peeling, grinding and micronisation), which reduced the enzymatic and antitrypsin factor contents so that the soyabean flour contained $80 \%$ of the nutritional value of animal casein.

The rats were weighed once per week throughout the experimental period. Food intake was recorded three times per week, and the data are expressed in absolute and relative values. To assess the relative food intake, the total food intake during the experimental period after weaning was normalised 
Table 1. Composition of the control, low-protein and soyabean diets

\begin{tabular}{lccc}
\hline & $\begin{array}{c}\text { Control } \\
\text { Ingredients }(\mathrm{g} / \mathrm{kg})\end{array}$ & $\begin{array}{c}\text { Low-protein } \\
\text { (17\% protein) }\end{array}$ & $\begin{array}{c}\text { Soyabean } \\
\text { flour }\end{array}$ \\
\hline Casein $(84 \%$ protein) & 202.0 & 71.5 & - \\
Soyabean flour & - & - & 415.0 \\
Maize starch & 397.0 & 480.0 & 312.2 \\
Dextrinised maize starch & 130.5 & 159.0 & 103.7 \\
Sucrose & 100.0 & 121.0 & 78.6 \\
Soyabean oil & 70.0 & 70.0 & - \\
Fibre & 50.0 & 50.0 & 40.0 \\
AIN-93G mineral mix $\dagger$ & 35.0 & 35.0 & 35.0 \\
AIN-93G vitamin mix† & 10.0 & 10.0 & 10.0 \\
L-Cystine & 3.0 & 1.0 & 3.0 \\
Choline bitartrate & 2.5 & 2.5 & 2.5 \\
\hline
\end{tabular}

AIN, American Institute of Nutrition.

* Composition of soyabean flour $(100 \mathrm{~g})$ : $455 \mathrm{kcal}(1903 \mathrm{~kJ}), 41 \mathrm{~g}$ carbohydrate, $25.5 \mathrm{~g}$ protein, $21 \mathrm{~g}$ total fat, $2 \mathrm{~g}$ fibre, $6 \mathrm{~g}$ humidity, $4.5 \mathrm{~g}$ ash, $100 \mathrm{mg}$ isoflavone. † See Reeves et al. ${ }^{(38)}$ for more details.

per $100 \mathrm{~g}$ body weight at age $90 \mathrm{~d}$. Food efficiency was defined as the ratio of body weight gain to food intake $\times 100$. Since it was not possible to evaluate all variables in the same animal, the number of individual experiments varied among the groups, but it was representative of at least four different litters.

\section{Unilateral denervation of brown adipose tissue}

While the rats were under diethyl ether anaesthesia, a small incision was made between the scapulae, and the interscapular BAT was carefully dissected from the surrounding muscle and WAT. Then, five branches of the right intercostal nerve bundles that contain sympathetic fibres entering the right side of the interscapular BAT were isolated and cut to a length of approximately $5 \mathrm{~mm}$. Surgical denervation was performed $7 \mathrm{~d}$ before the experiments were performed. Preliminary studies showed that $7 \mathrm{~d}$ after surgery, the noradrenalin content of the denervated side of the tissue was reduced to less than $2 \%$ of the control innervated side ${ }^{(19)}$. In addition, at $7 \mathrm{~d}$, the rates of fatty acid synthesis in the innervated side did not significantly differ from those in the BAT of rats without the operation.

\section{Sample collection and analysis}

${ }^{3} \mathrm{H}_{2} \mathrm{O}$ ( $3 \mathrm{mCi}$; Amersham Bioscience) dissolved in $0.5 \mathrm{ml}$ of saline ( $\mathrm{NaCl} 0.9 \%$; Labsynth Produtos para laboratório Ltda.) was administered to anaesthetised rats by intraperitoneal injections $1 \mathrm{~h}$ before the experiment to measure in vivo lipogenesis. BAT was removed from one group of rats and was separated into innervated and denervated portions, immediately weighed, frozen in liquid $\mathrm{N}_{2}$ and stored at $-80^{\circ} \mathrm{C}$ for a subsequent analysis of the lipid content, UCP-1 content or in vivo lipogenesis rates. From these animals, blood samples were collected and were allowed to clot; sera were subsequently stored at $-80^{\circ} \mathrm{C}$ for analyses of $\mathrm{T} 3$ and $\mathrm{T} 4$ levels by enzyme immunoassay (Interkit; BioCheck, Inc.). Another group of the innervated rats was subjected to the same treatment with ${ }^{3} \mathrm{H}_{2} \mathrm{O}$, and the retroperitoneal adipose tissue was removed, immediately weighed, frozen in liquid $\mathrm{N}_{2}$ and stored at $-80^{\circ} \mathrm{C}$ for a subsequent analysis of in vivo lipogenesis rates and lipid content. Finally, the remaining group was euthanised, blood samples were collected, serum was obtained by centrifugation and glucose was measured using the oxidase-peroxidase system ${ }^{(20)}$. Serum insulin concentrations were determined by RIA using rat insulin as the standard; ${ }^{125}$ I-labelled bovine insulin was used as the radioactive tracer, and guinea pig anti-porcine insulin serum was used as the antibody ${ }^{(21)}$. The physiological index of insulin resistance used was the homeostasis model assessment of insulin resistance (HOMA-IR), which was assessed from the fasting glucose and fasting insulin concentrations using the following formula: HOMA-IR $=($ fasting insulin $(\mathrm{pmol} / \mathrm{l})) \times($ fasting glucose $(\mathrm{mmol} / \mathrm{l})) / 22 \cdot 5$. Retroperitoneal tissue samples were quickly removed to determine lipolytic rates.

\section{Immunoblot}

Briefly, one fragment of BAT was excised and immediately homogenised in a freshly prepared buffer (100 mm-2-amino2-hydroxymethyl-propane-1,3-diol (Tris)- $\mathrm{HCl}, \quad \mathrm{pH} \quad 7 \cdot 4$; BioAgency Laboratorios); $100 \mathrm{mm-sodium} \mathrm{pyrophosphate}$ (FisherScientific), $100 \mathrm{~mm}$-sodium fluoride (J.T. Baker), $10 \mathrm{~mm}$ ethylenediaminetetraacetic acid (Labsynth Produtos para laboratório Ltda.), $10 \mathrm{~mm}$-sodium orthovanadate (Sigma-Aldrich), $2 \cdot 0 \mathrm{~mm}$-phenyl methyl sulfonyl fluoride (Alexis Biochemicals) and $0.1 \mathrm{mg}$ aprotinin $/ \mathrm{ml}$ (Sigma-Aldrich). Insoluble material was removed by centrifugation at $12000 \mathrm{~g}$ at $4{ }^{\circ} \mathrm{C}$ for $20 \mathrm{~min}$. The protein concentrations of the supernatants were determined by the Bradford method (Bio-Rad Laboratories, Inc.) ${ }^{(22)}$. Samples containing $60 \mu \mathrm{g}$ protein from each experimental group were incubated with $4 \times$ Laemmli sample buffer and $15 \mathrm{mg}$ dithiothreitol (Calbiochem, Inc.) and assayed on polyacrylamide (Acrylamide; BioAgency Laboratorios) gels at $120 \mathrm{~V}$ for $90 \mathrm{~min}$ (10\% gels for UCP-1). Electrotransfer (BioRad Laboratories, Inc.) of the proteins to nitrocellulose membranes (Bio-Rad Laboratories, Inc.) was performed for $90 \mathrm{~min}$ at $120 \mathrm{~V}$ in buffer containing methanol (Labsynth Produtos para laboratório Ltda.) and sodium dodecylsulfate (Bio-Rad Laboratories, Inc.). After checking transfer efficiency using Ponceau staining, the membranes were blocked with 5\% albumin (Sigma-Aldrich) in Tween-Tris-buffered saline (TTBS; $10 \mathrm{~mm}$-Tris, $150 \mathrm{mm-NaCl} / 1,0.5 \%$ Tween 20 (SigmaAldrich)) at $4{ }^{\circ} \mathrm{C}$ for $4 \mathrm{~h}$. Then, the membranes were incubated overnight with anti-UCP-1 rabbit polyclonal IgG (Chemicon International) and anti-glyceraldehyde 3-phosphate dehydrogenase rabbit polyclonal IgG (Invitrogen) diluted 1:500 in TTBS containing 3\% dried skimmed albumin. Enhanced chemiluminescence (Super Signal West Pico; Thermo Scientific) was used to detect the signals. Specific band intensities were measured using the Scion Image Program for Windows.

\section{In vivo lipogenesis measurements}

The in vivo rates of fatty acid synthesis were evaluated by the rate of incorporation of ${ }^{3} \mathrm{H}_{2} \mathrm{O}$ into BAT and retroperitoneal white adipose tissue (RWAT) fatty acids. At $1 \mathrm{~h}$ after ${ }^{3} \mathrm{H}_{2} \mathrm{O}$ 
injection, the animals were decapitated, and blood samples were collected to determine plasma water-specific radioactivity. The entire BAT or the right and left pads of the unilaterally denervated tissue were rapidly removed, carefully cleaned of adhering fat and muscle, and weighed. RWAT was removed and weighed. Tissue total lipids were extracted with chloroform-methanol (2:1), and ${ }^{3} \mathrm{H}_{2} \mathrm{O}$ was removed from the lower phase (predominantly chloroform) by washing three times with an upper-phase mixture ${ }^{(23)}$. After each shaking, the tubes were briefly centrifuged to sharpen the phase boundary, and the upper phase was aspirated and discarded. The chloroform (Labsynth Produtos para laboratório Ltda.) phase was evaporated until dry with $\mathrm{N}_{2}$, and TAG were hydrolysed with ethanolic $\mathrm{KOH}(1: 20)$ for $1 \mathrm{~h}$ at $70^{\circ} \mathrm{C}$. After extracting the non-saponifiable lipids and acidification with sulfuric acid, the ${ }^{3} \mathrm{H}$-labelled fatty acids were extracted with petroleum diethyl ether (Labsynth Produtos para laboratório Ltda.), and the extract was evaporated until dry in a scintillation vial and dissolved in toluene-2,5-diphenyloxazole for counting in a Beckman LS 7600 spectrometer. Body waterspecific activity was directly determined using aliquots of plasma diluted 1:20 in toluene-triton-2,5-diphenyloxazole. The rate of tissue fatty acid synthesis was calculated following the assumptions of Windmueller \& Spaeth ${ }^{(24)}$. The results are expressed as $\mu \mathrm{mol} / \mathrm{g}$ per $\mathrm{min}$.

\section{Lipid content}

The lipid contents of BAT and RWAT were determined by the gravimetric method following chloroform-methanol (2:1) extraction according to Folch et al. ${ }^{(23)}$.

\section{Adipocyte isolation}

RWAT was minced with fine scissors and added to a bottle containing Krebs-Ringer, 3\% fatty acid-free bovine serum albumin, $6 \mathrm{~mm}$-glucose (Sigma-Aldrich), and $1 \mathrm{mg} / \mathrm{ml}$ of collagenase (Sigma-Aldrich) type II and $\mathrm{pH} 7 \cdot 4$. The mixture was incubated for $45 \mathrm{~min}$ at $37^{\circ} \mathrm{C}$ in an orbital shaker (New Brunswick Scientific) at forty cycles per min. The isolated adipocytes were filtered through a fine nylon filter and washed three times in a 1:2 volume in the same buffer without collagenase. The cell suspensions were maintained in a hot water bath during the experiments. Adipocyte viability was tested with trypan blue (Sigma-Aldrich), and the cell number was determined as described previously ${ }^{(25)}$

\section{Lipolytic rate determination}

The washed adipocytes were diluted in Krebs-Ringer buffer containing 3\% bovine serum albumin (BSA) free fatty acid (Sigma A6003). Cells were counted in a Neubauer chamber, and the volume was subsequently corrected to obtain $10^{6}$ cells $/ \mathrm{ml}$ followed by pre-incubation for $15 \mathrm{~min}$ at $37^{\circ} \mathrm{C}$ with gentle shaking (forty cycles per min). The adipocytes were incubated with isoproterenol $\left(10^{5} \mathrm{M}\right.$; Sigma-Aldrich) and adenosine deaminase (15 U/ml (250 nkat/l); Sigma-Aldrich) with shaking for $1 \mathrm{~h}^{(26)}$. The reaction was blocked in an ice bath, the supernatant was decanted and the cells were aspirated. For the subsequent glycerol (Sigma-Aldrich) measurements using a Sigma-specific kit (Sigma-Aldrich), $400 \mu \mathrm{l}$ of the vehicle were stored at $-20^{\circ} \mathrm{C}$. The results were calculated as $\mathrm{mg}$ glycerol $/ \mathrm{dl} \times 10^{6}$ cells and are expressed as the percentage of basal levels of the isoproterenol effect. This determination was performed to evaluate isoproterenol stimulation.

\section{Statistical analysis}

Results are expressed as means with their standard errors for the number of rats indicated. Unpaired $t$ tests were used to analyse the size of the litters and the body weight of newborn rats. When examining the body weight of newborn rats, $n$ refers to the number of litters. Bartlett's test for the homogeneity of variances was initially used to determine whether the data complied with the assumptions necessary for a parametric ANOVA. When necessary, the data were logtransformed to correct for variance in heterogeneity or non-normality ${ }^{(27)}$. A three-way ANOVA (i.e. effects of previous nutritional status, diet and denervation or isoproterenol) was used to compare the data from the CC, CS, LC and LS groups. A two-way ANOVA (diet and denervation or isoproterenol) was used to compare the data from the LC, LS and LL

Table 2. Somatic profile of rats maintained with the control (CC and LC) or soyabean (CS and LS) or low-protein diets (LL)† (Means values with their standard errors for eight groups of four rats each)

\begin{tabular}{|c|c|c|c|c|c|c|c|c|c|c|}
\hline \multirow[b]{3}{*}{ Variables } & \multicolumn{10}{|c|}{ Groups } \\
\hline & \multicolumn{2}{|c|}{$\mathrm{CC}$} & \multicolumn{2}{|c|}{ CS } & \multicolumn{2}{|c|}{ LC } & \multicolumn{2}{|c|}{ LS } & \multicolumn{2}{|c|}{ LL } \\
\hline & Mean & SEM & Mean & SEM & Mean & SEM & Mean & SEM & Mean & SEM \\
\hline BW at weaning $(\mathrm{g})$ & $68 \cdot 4$ & 0.9 & $70 \cdot 1$ & 0.9 & $24.98^{*}$ & $0 \cdot 6$ & $25 \cdot 0^{*}$ & 0.5 & 24.9 & $0 \cdot 8$ \\
\hline Final BW $(\mathrm{g})$ & $512^{\mathrm{A}}$ & 10 & $407^{\mathrm{B}}$ & 4 & $331^{\mathrm{C}, \mathrm{a}}$ & 8 & $294^{\mathrm{D}, \mathrm{b}}$ & 8 & $168^{\mathrm{c}}$ & 9 \\
\hline Absolute food intake $(\mathrm{g})$ & 1214 & 51 & 1284 & 23 & $996^{\star a}$ & 8 & $966^{\star a}$ & 3 & $640^{\mathrm{b}}$ & 3 \\
\hline Relative food intake ( $\mathrm{g} / 100 \mathrm{~g} \mathrm{BW})$ & 271 & 10 & 274 & 11 & $281^{\mathrm{b}}$ & 11 & $273^{\mathrm{b}}$ & 6 & $405^{\mathrm{a}}$ & 16 \\
\hline Food efficiency & $36 \cdot 7^{A}$ & $1 \cdot 0$ & $26 \cdot 2^{\mathrm{C}}$ & 0.6 & $30 \cdot 6^{\mathrm{B}, \mathrm{a}}$ & 0.6 & $27 \cdot 7^{\mathrm{C}, \mathrm{b}}$ & 0.7 & $22 \cdot 3^{\mathrm{C}}$ & 0.9 \\
\hline
\end{tabular}

BW, body weight

$\mathrm{A}, \mathrm{B}, \mathrm{C}, \mathrm{D}$ Mean values with unlike superscript letters were significantly different $(P<0.05$; two-way ANOVA followed by least significant difference (LSD) test). a,b,c Mean values with unlike superscript letters were significantly different $(P<0.05$; one-way ANOVA followed by LSD test).

${ }^{*}$ Mean values were significantly different from those of the control rats $(P<0.05$; two-way ANOVA).

† See the Animals and diets section for a description of the diets and groups. 
groups. Moreover, a two-way ANOVA (effect of previous nutritional status and diet) was used to compare the data from the CC, CS, LC and LS groups. A one-way ANOVA was used to assess whether the diets were effective in improving the nutritional status of the LC, LS and LL groups. When necessary, these analyses were complemented by the least significant difference test to determine the significance of the individual differences. $P<0.05$ indicated statistical significance. All statistical comparisons were conducted using the Statistic software package (Stat-soft).

\section{Results}

Measurements of animal weight, retroperitoneal white adipose tissue and innervated and denervated brown adipose tissue weights, lipid content and food intake

The litter size from the $\mathrm{C}$ and LP groups was similar (11.0 (sE 0.3 ) pups and 10.5 (SE 0.3) pups, respectively), but the body weight of newborn LP rats was lower than that of the $\mathrm{C}$ rats $(4.78$ (SE 0.11$) \mathrm{g}$ and 5.54 (SE 0.24) g, respectively, $P<0 \cdot 01$ ). At the beginning of the recovery phase, the offspring born to and suckled by mothers fed a LP diet (LC, LS and LL groups) had similar body weights that were significantly lower than those of the offspring born to and suckled by mothers fed a C diet (CC and CS groups). At the end of this period, the body weight of the rats from the LC group was lower than that of the CC group $(P<0 \cdot 001)$. The soyabean diet significantly reduced the body weight in the LS and CS groups compared with the LC and CC groups $(P<0.01)$, respectively. While the $\mathrm{LS}$ rats had a greater body weight than the LL rats at the end of the experimental period, their weights were significantly lower than the LC rats. The absolute food intake was lower in the recovered rats (LC and LS) than in the controls (CC and CS) $\left(F_{1,28}=101.54 ; P<0.0001\right)$. In the LS and LC groups, the absolute food intake was similar, and both were significantly higher than the LL group. The relative food intake was similar in the LS, LC, CS and CC groups. However, the recovered groups (LC and LS) had a lower relative food intake compared with the LL group $(P<0 \cdot 001)$. The food efficiency was lower in the LC group than in the CC group, and both groups exhibited higher food efficiency values than the LS and CS groups $(P<0.001)$. The LL group had a lower food efficiency than the LC and LS groups $(P<0 \cdot 001$; Table 2).

The weight of the innervated BAT (mg/g body weight) in the LS group was higher than that in the LC, CC and CS groups. However, the BAT weights in the CC and CS groups were similar, while the BAT weights were lower in these groups when compared with the LC group $(P<0 \cdot 01)$. To evaluate the nutritional recovery, the BAT weights were similar in the LS and LC groups, but both weights were lower than that in the LL group $(P<0 \cdot 01)$. The denervated BAT weights ( $\mathrm{mg} / \mathrm{g}$ body weight) in the LC and LS groups were higher than those in the CC and CS groups $\left(F_{1,20}=14.54\right.$; $P<0 \cdot 001)$. The LC and LS groups had similar BAT weights, both of which were significantly lower than that of the LL group $(P<0 \cdot 001)$. The lipid content $(\mathrm{mg} / \mathrm{g}$ tissue $)$ in the

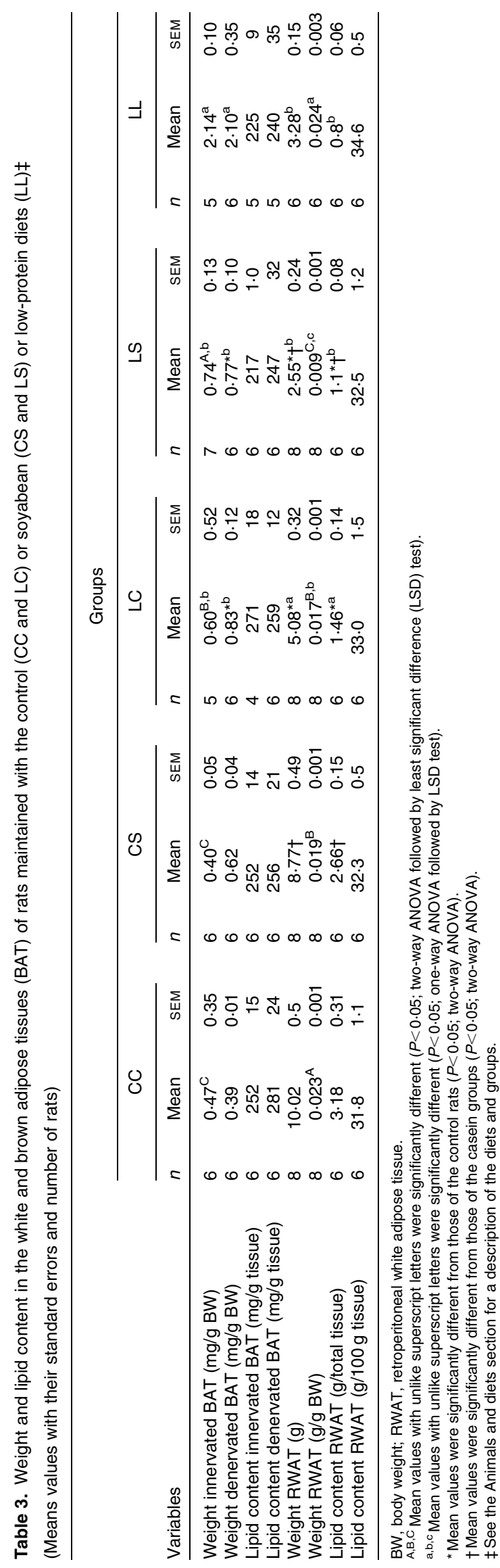


innervated and denervated BAT did not differ among the groups. The weight of RWAT was lower in the recovered rats (LC and LS) than in the controls (CC and CS) $\left(F_{1,28}=248.25 ; P<0.0001\right)$ and in rats fed a soyabean diet (CS and LS) compared with rats fed a casein diet (CC, LC) $\left(F_{1,28}=24.92 ; P<0.0001\right)$. The LS and LL groups had RWAT weights lower than the LC group. The relative weight of the RWAT ( $\mathrm{mg} / \mathrm{g}$ body weight) was lower in the LC group than in the CC group, and a soyabean diet reduced the weight of the RWAT in the LS and CS groups compared with the LC and CC groups, respectively $(P<0 \cdot 01)$. In the LS group, the relative weight of the RWAT was lower than that in the LC group, and both weights were lower than that in the LL group. The lipid content in the RWAT ( $\mathrm{mg} /$ total tissue) was lower in the LS and LC rats than in the CS and CC rats $\left(F_{1,20}=86.70, \quad P<0 \cdot 0001\right)$, as well as in the CS and LS groups compared with the CC and LC groups $\left(F_{1,20}=6 \cdot 27\right.$, $P<0.05$ ). In the LS and LL groups, the lipid content (mg/ total tissue) was similar, and both values were significantly lower than that of the LC group. However, the lipid content in the RWAT (mg/g tissue) did not differ among the groups (Table 3).

Serum T3 and T4, glucose and insulin concentrations and homeostasis model assessment of insulin resistance index

In the LC and LS groups, the T3 concentrations were decreased in comparison with the CC and CS groups $\left(F_{1,51}=5.62 ; P<0.02\right)$. Serum $\mathrm{T} 3$ concentration was similar in the LC and LS groups, but it was significantly lower in these groups than in the LL group $(P<0 \cdot 001)$. Serum T4 concentration in the LC, CS and CC groups was similar and higher when compared with the LS group $(P<0 \cdot 02)$. No difference was observed in T4 concentration between the LL and LS groups, but both were lower when compared with the LC group $(P<0 \cdot 001)$. Basal serum glucose levels were similar among the groups while serum insulin levels were lower in the recovered rats (LC and LS) than in the controls (CC and CS) $\left(F_{1,22}=5.50 ; P<0.04\right)$. In contrast, rats fed a soyabean diet (CS and LS) had higher insulinaemia than rats fed a casein diet $(\mathrm{CC}, \mathrm{LC})\left(F_{1,22}=14.48 ; P<0.001\right)$. HOMA-IR was lower in the recovered rats than in the controls $\left(F_{1,22}=5 \cdot 30\right.$; $P<0.03)$ and higher in rats fed a soyabean diet than in those fed a casein diet $\left(F_{1,26}=18.66 ; P<0.03\right)$. When evaluating nutritional recovery, similar glycaemia, insulinaemia and HOMA-IR levels were recorded among the LC, LS and LL groups (Table 4).

\section{Uncoupling protein 1 content}

The previous nutritional status had effects on the UCP-1 content of BAT ( $\left.F_{1,40}=9.53 ; P<0.003\right)$; the recovered groups (LC and LS) had lower UCP-1 levels than the controls (CC and CS). Unilateral denervation also modified UCP-1 levels; the denervated BAT had lower UCP-1 levels when compared with the innervated BAT $\left(F_{1,40}=18.88 ; P<0.0001\right)$, independent of the previous nutritional status and diet type. When evaluating nutritional recovery, similar UCP-1 content was observed in the LC, LS and LL groups, and unilateral denervation resulted in a significant reduction in all groups (Fig. 1).

\section{Rates of fatty acid synthesis in the innervated and denervated brown adipose tissue}

As shown in Fig. 2, higher rates of fatty acid synthesis were observed in the innervated BAT when compared with the denervated BAT $\left(F_{1,30}=6.88 ; P<0.02\right)$, independent of the previous nutritional status and diet type (i.e. soyabean or casein). Moreover, lipogenesis was similar in the LC and LS groups and lower when compared with the LL group $\left(F_{2,20}=8.60 ; P<0.002\right)$.

\section{Rates of fatty acid synthesis in retroperitoneal white adipose tissue}

In vivo lipogenesis rates in RWAT were not significantly influenced by previous nutritional status, post-weaning diet or the interaction between these factors. When evaluating nutritional recovery, lipogenesis was similar in the LC and LS groups and lower in both when compared with the LL group $(P<0 \cdot 02$; Fig. 3).

Table 4. Biochemical and hormonal parameters of rats maintained with the control (CC and LC) or soyabean (CS and LS) or low-protein diets (LL) $\ddagger$ (Means values with their standard errors and numbers of rats)

\begin{tabular}{|c|c|c|c|c|c|c|c|c|c|c|c|c|c|c|c|}
\hline \multirow[b]{3}{*}{ Variables } & \multicolumn{15}{|c|}{ Groups } \\
\hline & \multicolumn{3}{|c|}{$\mathrm{CC}$} & \multicolumn{3}{|c|}{ CS } & \multicolumn{3}{|c|}{ LC } & \multicolumn{3}{|c|}{ LS } & \multicolumn{3}{|c|}{$\mathrm{LL}$} \\
\hline & $n$ & Mean & SEM & $n$ & Mean & SEM & $n$ & Mean & SEM & $n$ & Mean & SEM & $n$ & Mean & SEM \\
\hline T3 (ng/ml) & 15 & $4 \cdot 8$ & 0.3 & 14 & 4.3 & 0.4 & 12 & $4 \cdot 0^{\star b}$ & 0.4 & 14 & $3 \cdot 6^{\star b}$ & 0.3 & 12 & $5 \cdot 7^{\mathrm{a}}$ & 0.4 \\
\hline $\mathrm{T} 4((\mathrm{~g} / \mathrm{l})$ & 15 & $65^{\mathrm{A}}$ & 5 & 15 & $65^{\mathrm{A}}$ & 3 & 12 & $68^{\mathrm{A}, \mathrm{a}}$ & 6 & 14 & $50^{\mathrm{B}, \mathrm{b}}$ & 3 & 12 & $52^{b}$ & 3 \\
\hline Glucose $(\mathrm{mmol} / \mathrm{l})$ & 8 & 3.6 & 0.3 & 5 & 4.0 & 0.4 & 7 & 3.7 & 0.4 & 6 & 3.7 & 0.4 & 5 & $3 \cdot 1$ & 0.6 \\
\hline Insulin (pmol//) & 8 & 88.58 & 31.37 & 5 & 179.73† & 74.70 & 7 & $75 \cdot 41^{*}$ & 22.92 & 6 & $114 \cdot 45^{\star} \dagger$ & 35.92 & 5 & $80 \cdot 81$ & $22 \cdot 10$ \\
\hline HOMA-IR & 8 & $13 \cdot 4$ & $3 \cdot 4$ & 5 & $30.9 \dagger$ & $12 \cdot 6$ & 7 & $12 \cdot 9^{\star}$ & $5 \cdot 7$ & 6 & $17 \cdot 6^{*} \dagger$ & 2.59 & 5 & $11 \cdot 6$ & $6 \cdot 3$ \\
\hline
\end{tabular}

HOMA-IR, homeostasis model assessment of insulin resistance.

${ }_{A, B}$ Mean values with unlike superscript letters were significantly different $(P<0.05$; two-way ANOVA followed by least significant difference (LSD) test).

${ }^{a, b}$ Mean values with unlike superscript letters were significantly different $(P<0.05$; one-way ANOVA followed by LSD test).

${ }^{\star}$ Mean values were significantly different from those of the control rats (two-way ANOVA).

$\dagger$ Mean values were significantly different from those of the casein groups (two-way ANOVA).

$\ddagger$ See the Animals and diets section for a description of the diets and groups. 


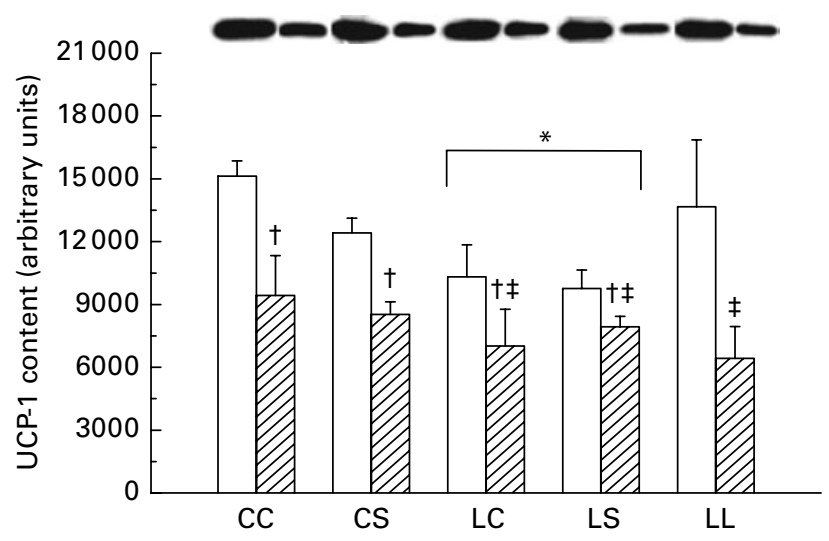

Fig. 1. Uncoupling protein 1 (UCP-1) content in brown adipose tissue (BAT) from rats maintained with the control (CC and LC groups) or soyabean (CS and LS groups) or low-protein (LL group) diets at age $90 \mathrm{~d}$. See the Animals and diets section for a description of the diets and groups. Values are means, with their standard errors represented by vertical bars ( $n$ 5-6 animals). * Mean values were significantly different from the control rats $(P<0.05$; three-way ANOVA). † Mean values were significantly different from the innervated $(\square)$ BAT $(P<0.05$; three-way ANOVA). $¥$ Mean values were significantly different from those of the LC, LS and LL innervated BAT $(P<0.05$; two-way ANOVA). $\mathbb{Z}$, Denervated.

\section{Lipolysis in retroperitoneal white adipose tissue}

In the basal state, glycerol released by RWAT was similar, and the presence of isoproterenol incremented the glycerol release in all groups. However, stimulation with isoproterenol resulted in a lower lipolysis rate in the LS group when compared with the LC, CS and CC groups. Moreover, isoproterenol elicited similar lipolysis rates in the CS and LC groups, both of which had more released glycerol than the CC group. When evaluating nutritional recovery, the basal lipolysis rate was similar in the LS and LL groups and both were lower than the LC group. Isoproterenol induced significantly different lipolysis rates among the LL, LC and LS rats. The highest lipolysis rate was observed in the LL group, followed by the LC group. The lowest glycerol release was in the LS group (Fig. 4).

\section{Discussion}

In the present study, malnutrition during a critical period of development resulted in permanent somatic deficits independent of dietary protein quality during nutritional rehabilitation. In addition, rats fed a soyabean diet had similar relative food intakes but lower body weights, lower RWAT weights and decreased RWAT lipid content when compared with rats fed a casein diet, which is in accordance with the results of a previous study ${ }^{(2)}$. A soyabean diet has been associated with a reduction in fat deposits due to the action of isoflavones, which increase energy expenditure by altering the BAT activity and thyroid function ${ }^{(1,4)}$. It has been demonstrated that the thermogenic capacity of BAT is primarily due to the expression of UCP-1, which can dissipate the proton gradient across the inner mitochondrial membrane and produce heat ${ }^{(28)}$. Although animals fed a soyabean diet had a considerable amount of serum genistein level ${ }^{(29)}$, this isoflavone did not influence serum thyroid hormone levels or UCP-1 content.
In line with studies that have suggested that UCP-1 content is modified by thyroid hormones and insulin ${ }^{(4,30)}$, there was a direct association in the present study between UCP-1 expression and serum concentration of these hormones, at least in the recovered rats, and this effect was independent of protein quality. Neural factors (namely noradrenalin) influence UCP-1 content in the BAT ${ }^{(4,30)}$. The soyabean diet did not alter UCP-1 expression induced by the sympathetic flux in the present study, as denervation of interscapular BAT equally decreased UCP-1 in all groups.

Curiously, the expected increase in UCP-1 content induced by a high-carbohydrate diet ${ }^{(31)}$ and the augmented dietinduced thermogenesis due to hyperphagia caused by decreased food efficiency ${ }^{(6,32)}$ were not observed in our LL group. Also, an inverse correlation between UCP-1 content and food efficiency was not observed in the recovered rats (LS and LC groups) or in the CS rats. However, a lower calculated energy expenditure previously reported in recovered rats $^{(2)}$ was accompanied by reduced UCP-1 content in the present study.

In vivo fatty acid synthesis in BAT is directly dependent on the effects of sympathetic activity and insulin availability, both favouring glucose uptake, which is the main substrate of fatty acid synthesis. In the present study, although denervation contributed to a reduction in in vivo fatty acid synthesis, this occurred mainly in the control groups, especially the CS group. This observation is reinforced by the profile of the LS, LC and LL groups, as their fatty acid synthesis was not modified by interrupting the sympathetic flux. The lack of impairment in in vivo fatty acid synthesis in BAT after denervation as well as the similar HOMA-IR and serum insulin levels in the recovered and malnourished rats indicate little neural contribution but important insulin contribution to lipogenesis in BAT from those groups. The latter assumption is because the reduced serum insulin levels and low HOMA-IR

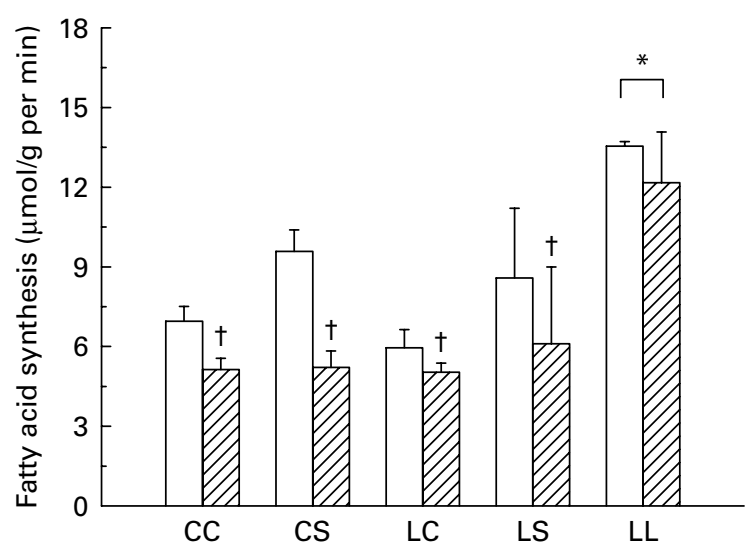

Fig. 2. Rates of lipogenesis in brown adipose tissue (BAT) from rats maintained with the control (CC and LC groups) or soyabean (CS and LS groups) or low-protein (LL group) diets at age $90 \mathrm{~d}$. See the Animals and diets section for a description of the diets and groups. Values are means, with their standard errors represented by vertical bars ( $n$ 8-9 animals). * Mean values were significantly different from those of the LC and LS rats $(P<0.05$; two-way ANOVA). † Mean values were significantly different from those of the innervated $(\square)$ BAT $(P<0.05$; three-way ANOVA). $\square$, Denervated. 


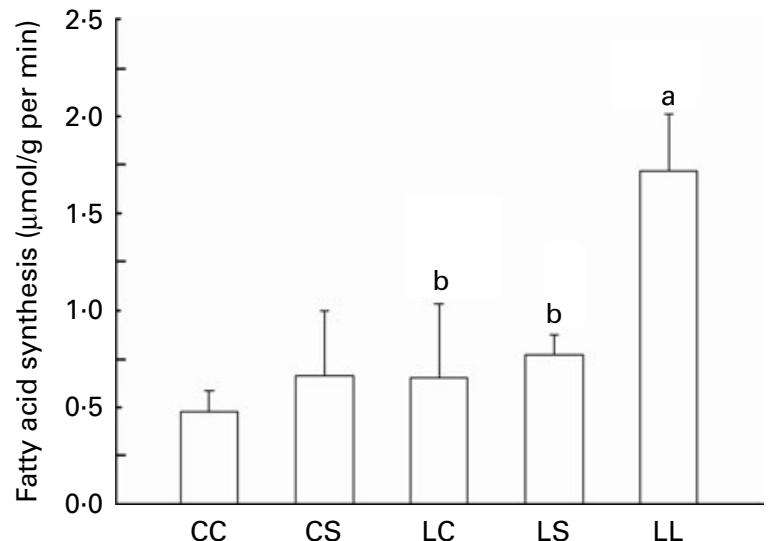

Fig. 3. Rates of lipogenesis in RWAT from rats maintained with the control (CC and LC groups) or soyabean (CS and LS groups) or low-protein (LL group) diets at age $90 \mathrm{~d}$. See the Animals and diets section for a description of the diets and groups. Values are means, with their standard errors represented by vertical bars ( $n 4-5$ animals). ${ }^{\mathrm{a}, \mathrm{b}}$ Mean values with unlike letters were significantly different $(P<0.05$; one-way ANOVA followed by least significant difference test)

in those groups indicate increased insulin sensitivity. Another factor possibly contributing to the increased in vivo fatty acid synthesis in BAT from the LL rats could be due to high carbohydrate levels in the low-protein diet. It has been suggested that malic enzyme and citrate lyase activities are stimulated by high carbohydrate levels ${ }^{(33)}$. In vivo fatty acid synthesis in BAT, especially in the LL, LC and LS groups, correlated with innervated BAT weight but was not related to lipid content. Thus, the hypertrophy of BAT in the LL group did not occur due to an increase in lipid content. Taking into account that the increase in BAT thermogenic activity and the enhancement of fatty acid oxidation induced by diet-induced thermogenesis are accompanied by a simultaneous elevation in fatty acid synthesis $^{(6,8)}$, we suggest that BAT thermogenic activity was enhanced, at least in the LL rats.

Contrary to studies that have suggested that genistein ${ }^{(34)}$ and soya protein ${ }^{(35)}$ suppress lipogenesis in WAT, a soyabean diet did not alter in vivo fatty acid synthesis in RWAT. However, those studies were accomplished in distinct experimental model or the conclusions were supported by results from the indirect assessment of lipogenesis (the sterol regulatory element-binding protein-1 expression). A surprising finding was the unaltered in vivo fatty acid synthesis in RWAT, despite increased serum insulin levels, especially in the CS group. We have recently demonstrated that under the same experimental conditions, the soyabean diet elevated serum insulin concentration and reduced acetyl-coenzyme A carboxylase in the liver, especially in the CS group ${ }^{(36)}$. Moreover, a decrease in liver lipogenesis associated with low ATP-citrate lyase and malic enzyme activities in the CS and LS groups was observed (SRL Reis, NH Feres, LMI Souza, RV Veloso, VC Arantes, NH Kawashita, EM Colodel, BL Botosso, EM Carneiro, AC Boschero, MAB Reis and MQ Latorraca, unpublished results). Hyperinsulinaemia and hyperglycaemia have been suggested as important stimuli for the increased fat synthesis. A possible explanation for the paradoxical increase in serum insulin concentration associated with unmodified or reduced de novo lipogenesis in the RWAT and in the liver is the mild hyperinsulinaemia, mild insulin resistance and euglycaemia observed in our animals fed a soyabean diet. The increased de novo lipogenesis associated with low insulin levels in RWAT from the LL group was not surprising because this low-protein diet has a high carbohydrate content.

Isoproterenol stimulation evoked lower lipolytic rates in RWAT adipocytes from the LS rats when compared with the CS rats. Interestingly, both groups had similar serum genistein levels ${ }^{(29)}$, weakening the hypothesis that this isoflavone enhances adrenalin-induced lipolysis ${ }^{(34)}$, at least in the LS group. In addition, it has been shown that rats fed a low-protein diet during early life and recovered after weaning have elevated plasma adrenalin and noradrenalin concentrations in the fed state and increased $\beta$-adrenergic receptor expression in WAT $^{(37)}$. Accordingly, isoproterenol enhanced the lipolytic rate in adipocytes from the LC and LL groups in the present study. Thus, we speculate that the low responsiveness to isoproterenol exhibited by adipocytes from the LS group could be a result of reduced $\beta$-adrenergic receptor expression elicited by nutritional recovery with a soyabean diet.

Fat accumulation is determined by the balance between fat synthesis (lipogenesis) and fat breakdown (lipolysis/fatty acid oxidation). In the present study, the lipolysis rate appeared to determinate the RWAT lipid content; the lipogenesis rate was similar in all groups, except in the LL group, which had exacerbated lipogenesis. Thus, the low lipolysis rate of the LS group contributed to the preservation of lipids at the expense of other tissue components, considering the values of the relative RWAT weight and lipid content. In the LC group, an intermediate lipolysis rate and the relative RWAT weight were observed with elevated RWAT lipid content, reflecting increased lipid accumulation in that tissue. In the LL group, the lipolysis rate paralleled the lipogenesis rate and resulted in a low lipid content associated with an elevated

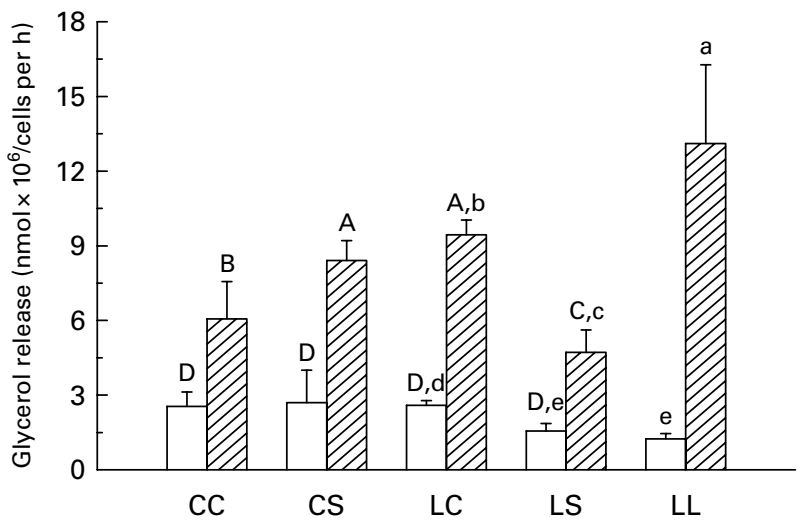

Fig. 4. Lipolysis in RWAT from rats maintained with the control (CC and LC groups) or soyabean (CS and LS groups) or low-protein (LL group) diets at age $90 \mathrm{~d}$. See the Animals and diets section for a description of the diets and groups. Values are means, with their standard errors represented by vertical bars (n 4-5 animals). A,B,C,D Mean values with unlike letters were significantly different $(P<0.05$; three-way ANOVA followed by least significant difference (LSD) test). ${ }^{\mathrm{a}, \mathrm{b}, \mathrm{c}, \mathrm{d}, \mathrm{e}}$ Mean values with unlike letters were significantly different $(P<0.05$; two-way ANOVA followed by LSD test). $\square$, Basal; $\nabla$, isoproterenol. 
relative RWAT weight, indicating the presence of other tissue components in addition to lipids. In the CS group, increased lipolysis rates contributed to a reduction in lipid accumulation in RWAT and consequent decreases in the relative RWAT weight.

\section{Conclusions}

A relevant finding of the present study was that the soyabean diet did not affect the thermogenic capacity of BAT but did produce distinct changes in the lipid metabolism of RWAT depending on previous nutritional status. In the offspring of mothers fed a normal-protein diet during pregnancy and lactation, a soyabean diet after weaning reduced fat accumulation by increasing the lipolysis rate. However, in the offspring of mothers fed a low-protein diet during pregnancy and lactation, a soyabean diet after weaning preserved the fat content in RWAT because of a reduced lipolysis rate.

\section{Acknowledgements}

We thank Celso Roberto Afonso for technical assistance and American Journal Experts (www.journalexperts.com) for English editing. This study was supported by the Brazilian Foundations FAPEMAT (grant no. 741/06). Adriene Alexandra Paiva was the recipient of a CAPES fellowship. The authors' contributions are as follows: A. A. P. participated in all of the study including the drafting of the manuscript; J. Z. F. and M. S. T. participated in the experimental phase; S. R. d. L. R. participated in the experimental phase and the statistical analysis; N. H. K. and M. P. S. offered technical support in BAT denervation and lipogenesis analysis; H. F. R. offered technical support in the lipolysis analysis; H. C. F. d. O. performed the standardisation of the lipolysis analysis; E. M. C. offered technical support in the lipogenesis analysis; V. E. C. participated in the analysis of the results; M. Q. L. performed the statistical analysis; M. H. G. G. d. S. participated in the preparation of the manuscript; M. S. F. M. participated in the design, coordination of the study, and the drafting of the manuscript. All authors read and approved the final manuscript. The authors declare that there are no conflicts of interest.

\section{References}

1. Lephart ED, Porter JP, Lund TD, et al. (2004) Dietary isoflavones alter regulatory behaviors, metabolic hormones and neuroendocrine function in Long-Evans male rats. Nutr Metab (Lond) 1, 16.

2. Cheim LM, Oliveira EA, Arantes VC, et al. (2009) Effect of nutritional recovery with soybean flour diet on body composition, energy balance and serum leptin concentration in adult rats. Nutr Metab (Lond) 6, 34 .

3. Torre-Villalvazo I, Tovar AR, Ramos-Barragán VE, et al. (2008) Soy protein ameliorates metabolic abnormalities in liver and adipose tissue of rats fed a high fat diet. $J$ Nutr 138, 462-468.

4. Takahashi Y \& Ide $T$ (2008) Effects of soy protein and isoflavone on hepatic fatty acid synthesis and oxidation and mRNA expression of uncoupling proteins and peroxisomeproliferator-activated receptor $\gamma$ in adipose tissues of rats. J Nutr Biochem 19, 682-693.

5. Cannon B \& Nedergaard J (2004) Brown adipose tissue: function and physiological significance. Physiol Rev 84, $277-359$.

6. Rothwell NJ, Stock MJ \& Tyzbir RS (1982) Energy balance and mitochondrial function in liver and brown fat of rats fed 'cafeteria' diets of varying protein content. Nutrition 112, 1663-1672.

7. Ribeiro MO, Carvalho SD, Schultz JJ, et al. (2001) Thyroid hormone sympathetic interaction and adaptive thermogenesis are thyroid hormone receptor isoform-specific. J Clin Invest 108, 97-105.

8. Himms HJ (1989) Brown adipose tissue thermogenesis and obesity. Prog Lipid Res 28, 67-115.

9. Shimazu T \& Takahashi A (1980) Stimulation of hypothalamic nuclei has differential effects on lipid synthesis in brown and white adipose tissue. Nature 284, 62-63.

10. Takahashi A \& Shimazu T (1982) Hypothalamic regulation of lipid metabolism in the rat: effect of hypothalamic stimulation on lipogenesis. J Auton Nerv Syst 6, 225-235.

11. Minokoshi Y, Saito M \& Shimazu T (1988) Sympathetic activation of lipid synthesis in brown adipose tissue in the rat. J Physiol 398, 361-370.

12. McCormack JG \& Denton RM (1977) Evidence that fatty acid synthesis in the interscapular brown adipose tissue of coldadapted rats is increased in vivo by insulin by mechanisms involving parallel activation of pyruvate dehydrogenase and acetyl-coenzyme A carboxylase. Biochem $J \mathbf{1 6 6}$, 627-630.

13. McCormack JG (1982) The regulation of fatty acid synthesis in brown adipose tissue by insulin. Prog Lipid Res 21, 195-223.

14. Kawashita NH, Moura MA, Brito MN, et al. (2002) Relative importance of sympathetic outflow and insulin in the reactivation of brown adipose tissue lipogenesis in rats adapted to a high-protein diet. Metabolism 51, 343-349.

15. Pénicaud L, Cousin B, Leloup C, et al. (2000) The autonomic nervous system, adipose tissue plasticity, and energy balance. Nutrition 16, 903-908.

16. Lafontan M, Berlan M, Galitzky J, et al. (1992) Alpha-2 adrenoceptors in lipolysis: alpha 2 antagonists and lipidmobilizing strategies. Am J Clin Nutr 55, 219-227.

17. Jaworski K, Sarkadi-Nagy E, Duncan ER, et al. (2007) Regulation of triglyceride metabolism. IV. Hormonal regulation of lipolysis in adipose tissue. Am J Physiol Gastrointest Liver Physiol 293, G1-G4.

18. Comissão de Ensino do Colégio Brasileiro de Experimentação Animal (COBEA) (1996) Manual para técnicos em laboratórios, 2nd ed. São Paulo, SP: Andrade A (Org.).

19. Garofalo MA, Kettelhut IC, Roselino JE, et al. (1996) Effect of acute cold exposure on norepinephrine turnover rates in rat white adipose tissue. J Auton Nerv Syst 60, 206-208.

20. Trinder P (1969) Determination of blood glucose using an oxidase-peroxidase system with a non-carcinogenic chromogen. J Clin Path 22, 158-161.

21. Scott AM, Atwater I \& Rojas E (1981) A method for the simultaneous measurement of insulin release and B-cell membrane potential in single mouse islets of Langerhans. Diabetologia 21, 470-475.

22. Bradford MM (1976) A rapid and sensitive method for the quantitation of microgram quantities of protein utilizing the principle of protein-dye binding. Anal Biochem $\mathbf{7 2}$, $248-254$. 
23. Folch J, Lees M \& Sloane Stanley GH (1957) A simple method for the isolation and purification of total lipides from animal tissues. J Biol Chem 226, 497-509.

24. Windmueller HG \& Spaeth AE (1966) Perfusion in vivo with tritium oxide to measure hepatic lipogenesis and lipid secretion. J Biol Chem 241, 2891-2899.

25. Rodbell M (1964) Metabolism of isolated fat cells. I. Effects of hormones on glucose metabolism and lipolysis. J Biol Chem 239, 375-380.

26. Honnor RC, Dhillon GS \& Londos C (1985) cAMP-dependent protein kinase and lipolysis in rat adipocytes. I. Cell preparation, manipulation, and predictability in behavior. $J$ Biol Chem 260, 15122-15129.

27. Sokal RR \& Rohlf FJ (1995) Assumptions of analysis of variance. In Biometry: The Principles and Practice of Statistics in Biological Research, pp. 392-450 [RR Soka and FJ Rohlf, editors]. New York, NY: WH Freeman and Company.

28. Nicholls DG \& Locke RM (1984) Thermogenic mechanisms in brown fat. Physiol Rev 64, 1-64.

29. de Arruda Oliveira E, Gomes Cheim LM, Veloso RV, et al. (2008) Nutritional recovery with a soybean flour diet improves the insulin response to a glucose load without modifying glucose homeostasis. Nutrition 24, 76-83.

30. Valverde AM \& Benito M (2005) The brown adipose cell: a unique model for understanding the molecular mechanism of insulin resistance. Med Chem 5, 269-278.
31. Sundin U \& Nechad M (1983) Trophic response of rat brown fat by glucose feeding: involvement of sympathetic nervous system. Am J Physiol 244, 142-149.

32. Specter SE, Hamilton JS, Stern JS, et al. (1995) Chronic protein restriction does not alter energetic efficiency or brown adipose tissue thermogenic capacity in genetically obese (fa/fa) Zucker rats. J Nutr 125, 2183-2193.

33. Boll M, Weber LW \& Stampfl A (1996) Nutritional regulation of the activities of lipogenic enzymes of rat liver and brown adipose tissue. $Z$ Naturforsch $C$ 51, 859-869.

34. Szkudelska K, Nogowski L \& Szkudelski T (2000) Genistein affects lipogenesis and lipolysis in isolated rat adipocytes. J Steroid Biochem Mol Biol 75, 265-271.

35. Tovar AR, Torre-Villalvazo I, Ochoa M, et al. (2005) Soy protein reduces hepatic lipotoxicity in hyperinsulinemic obese Zucker fa/fa rats. J Lipid Res 46, 1823-1832.

36. Milanski M, Souza KL, Reis SR, et al. (2009) Soybean diet modulates acetyl-coenzyme A carboxylase expression in livers of rats recovering from early-life malnutrition. Nutrition 25, 774-781.

37. Petry CJ, Dorling MW, Wang CL, et al. (2000) Catecholamine levels and receptor expression in low protein rat offspring. Diabet Med 17, 848-853.

38. Reeves PG, Nielsen FH \& Fahey GC Jr (1993) AIN-93 purified diets for laboratory rodents: final report of the American Institute of Nutrition ad hoc writing committee on the reformulation of the AIN-76A rodent diet. J Nutr 123, 1939-1951. 